\title{
Taskforce aims to bolster rural physicians
}

$\mathrm{H}$ aving worked in the interior of British Columbia since 1989, Dr. John Soles life as a rural family physician has been nothing like his urban colleagues. He has done "the full spectrum," he says, from delivering babies and treating colds to mentoring young physicians and managing the business side of his practice.

"It's about how to work with fewer resources and always dealing with a degree of uncertainty," says Soles, president of the Society of Rural Physicians of Canada (SRPC).

Although about $18 \%$ of Canadians live in rural or remote areas, only $14 \%$ of family physicians practise there. Adding to their stress is the fact that family physicians provide $85 \%$ of primary care needs.

To help tackle these and other challenges, the SRPC and the College of Family Physicians of Canada (CFPC) created the Advancing Rural Family Medicine (ARFM) Canadian Collaborative Taskforce, which released a background paper in January.

The Review of Family Medicine Within Rural and Remote Canada: Education, Practice, and Policy outlines how to help family physicians acquire, maintain and enhance the competencies and resources they need to provide comprehensive care in rural and remote areas.

The taskforce, founded in 1999, has helped boost the number of family medicine graduates practising in rural areas by more than $10 \%$ between 2008 and 2012. This exceeds the growth in rural populations. However, challenges persist with respect to recruitment, retention, infrastructure and resources to promote rural practice.

Dr. Ruth Wilson, the taskforce cochair from the CFPC, says "Financial incentives aren't a panacea," noting that physicians recruited to work in rural communities often leave when incentives end.

Tackling the problem will require cooperation and coordination among

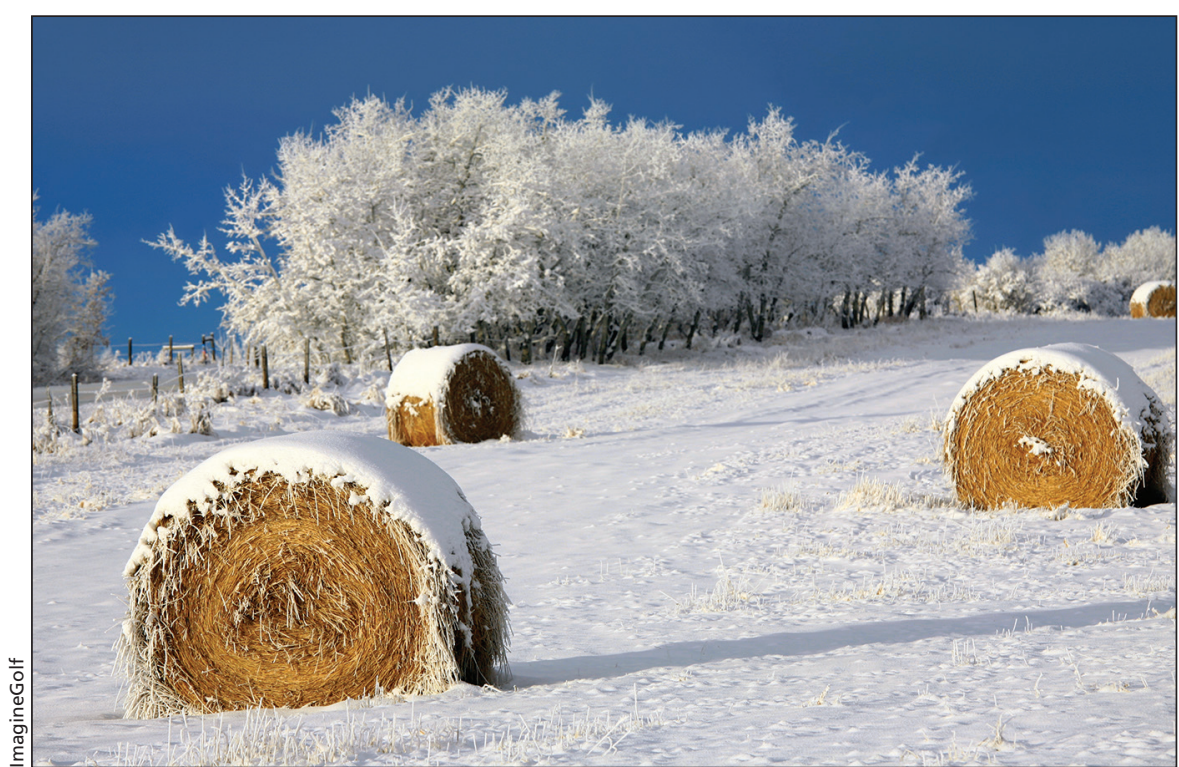

Some $18 \%$ of Canadians live in rural or remote areas, where only $14 \%$ of family physicians practise.

stakeholders, Wilson says. Different systems of recruitment and retention in different provinces make things tricky. For example, when the pay for a rural physician is higher in one province, it can inadvertently poach physicians from its neighbour, leaving rural communities there with less care.

"We don't have a coordinating body to bring them all together," says Wilson. The report recommends a pan-Canadian approach, including sharing recruitment and retention strategies among provinces, as well as national leadership to coordinate efforts between governments, medical schools and physician groups.

However, recruitment and retention are not the only issues. Many young rural physicians are highly knowledgeable and competent as physicians, says Soles, but "what they lack is confidence."

Rural family medicine is not like family medicine in urban areas, he stresses. A successful rural family physician is "a rational risk-taker."

Medical schools need to better align education and practice, and choose potential physicians bests suited for rural life, he adds.
Making sure the right students and the right physicians are making their way to rural communities starts well before medical school, Wilson says.

"We need to recruit more students from rural backgrounds and indigenous backgrounds, even in high school," she says. "Sometimes the people who would make excellent doctors aren't even encouraged to think about it."

The report calls for an improvement in rural education infrastructure. Rural clinical teaching sites now play a more important role in the training of physicians. However, the infrastructure to support clinical teachers in rural areas, from sufficient numbers of distributed medical education sites to consistent clinical curricula or human resource approaches, is often lacking, according to the paper.

Over the next year, the taskforce will consult with stakeholders and develop recommendations as part of building a pan-Canadian rural road map that they plan to release in 2017. Michael Colborne, Edmonton, Alta.

CMAJ 2016. DOI:10.1503/cmaj.109-5236 